\title{
Automated DNA extraction platforms offer solutions to challenges of assessing microbial biofouling in oil production facilities
}

\author{
Athenia L Oldham ${ }^{1,2,3^{*}}$, Heather S Drilling ${ }^{1,2}$, Blake W Stamps ${ }^{1,2}$, Bradley S Stevenson ${ }^{1,2}$ \\ and Kathleen E Duncan 1,2,3
}

\begin{abstract}
The analysis of microbial assemblages in industrial, marine, and medical systems can inform decisions regarding quality control or mitigation. Modern molecular approaches to detect, characterize, and quantify microorganisms provide rapid and thorough measures unbiased by the need for cultivation. The requirement of timely extraction of high quality nucleic acids for molecular analysis is faced with specific challenges when used to study the influence of microorganisms on oil production. Production facilities are often ill equipped for nucleic acid extraction techniques, making the preservation and transportation of samples off-site a priority. As a potential solution, the possibility of extracting nucleic acids on-site using automated platforms was tested. The performance of two such platforms, the Fujifilm QuickGene-Mini80 ${ }^{\mathrm{TM}}$ and Promega Maxwell ${ }^{\circledR} 16$ was compared to a widely used manual extraction kit, MOBIO PowerBiofilm ${ }^{\mathrm{TM}}$ DNA Isolation Kit, in terms of ease of operation, DNA quality, and microbial community composition. Three pipeline biofilm samples were chosen for these comparisons; two contained crude oil and corrosion products and the third transported seawater. Overall, the two more automated extraction platforms produced higher DNA yields than the manual approach. DNA quality was evaluated for amplification by quantitative PCR (qPCR) and end-point PCR to generate 454 pyrosequencing libraries for 165 rRNA microbial community analysis. Microbial community structure, as assessed by DGGE analysis and pyrosequencing, was comparable among the three extraction methods. Therefore, the use of automated extraction platforms should enhance the feasibility of rapidly evaluating microbial biofouling at remote locations or those with limited resources.
\end{abstract}

Keywords: 165 rRNA gene, Automated nucleic acid extraction platforms, Microbial biofouling, Bacterial community, Oilfield microbiology

\section{Introduction}

Microbial biofouling is a significant problem facing many different systems including industrial (e.g. fuel production, food production, drinking-water, etc.), marine (e.g. ship ballast tanks) and medical (e.g. catheters) (Bixler and Bhushan 2012). Biofilm formation, or the accumulation of water-borne microorganisms and their associated extrapolymeric substances (EPS) on wetted surfaces, is a major contributor to biofouling and

\footnotetext{
* Correspondence: athenia.L.oldham-1@ou.edu

'The Department of Microbiology and Plant Biology, University of Oklahoma, 770 Van Vleet Oval GLCH \#136, Norman, OK 73019, USA

2University of Oklahoma Biocorrosion Center, Norman, OK 73019, USA

Full list of author information is available at the end of the article
}

becomes an economic liability when it exceeds some threshold of interference, resulting in material damage, production loss, or elevated health risks (Murthy and Venkatesan 2009). Therefore, rapid sample processing and analysis is necessary for prompt microbial biofouling assessment. Due to limited space, resources, or expertise, samples from the facilities at risk are often shipped to research or commercial laboratories for nucleic acid extraction and analysis, where the efficacy of antifouling approaches, such as biocide treatment or physical biofilm removal (Quarini and Shire 2007), can be rapidly deduced using molecular-based approaches. These approaches include amplification of both the 16S rRNA gene and functional genes to identify specific microbes 
and qPCR to quantify target genes (Smith and Osborn 2009). The caveats of shipping samples for extraction in lieu of extracting on-site include: 1) shipping materials that could be considered "hazardous," and 2) the microbial community structure of the sample could shift during the time in transit from facility to lab, leading to erroneous results. Therefore, the ability to extract nucleic acids on-site and within hours of sampling could bypass these two caveats and hasten microbial biofouling assessment and treatment.

Successful molecular-based studies rely on extraction of high-quality nucleic acids from complex samples (i.e. production waters, biofilm material, sediment, etc.). These types of samples can contain factors that interfere with cell lysis, nucleic acid capture, or polymerase activity (Wilson 1997). Therefore, improvements in extraction performance, such as increased lysis or inhibitorremoval technologies increase the likelihood of obtaining nucleic acids for use in downstream PCR-based applications (van Der Kraan et al. 2011). All nucleic acid extraction protocols require the same basic steps: cell lysis to release nucleic acids from microbes, removal of inhibitors that can interfere with downstream applications, and nucleic acid mobilization, purification, and elution into a suitable buffer. The ease of use and time requirements, however, will vary based on the degree of automation and requirements for additional equipment (Table 1). Due to the complexity of industrial and environmental sample types, commercially available kits are recommended for distinct sample types. While kits have made extracting DNA and RNA from complex samples feasible in a laboratory setting, the manual steps and additional equipment requirements which often include an incubator, microcentrifuge, and physical lysis equipment make preparation difficult for personnel with limited training, few laboratory resources, or in remote locations.

Our lab has extensive experience with traditional phenol-chloroform DNA extractions and with using a broad array of commercially available extraction kits, both of which require ancillary laboratory equipment. The goal of this study was to test the feasibility of using more automated extraction approaches on biofilm material scraped from oilfield pipelines, as an example of the types of complex samples encountered in industrial situations. We hypothesized that the two automated platforms chosen would perform equivalently to a widely used manual extraction kit when compared by a set of standard PCR-based analyses. The rationale for this study was to determine if more automated extraction platforms would enable personnel, untrained in molecular biology or with limited laboratory resources, to extract DNA on-site and within hours to preserve sample integrity. The two automated extraction platforms tested were the semi-automated QuickGene-Mini80 ${ }^{\mathrm{TM}}$ (Autogen/FujiFilm, Holliston, MA) and the automated

Table 1 Comparison of DNA extraction platforms

\begin{tabular}{|c|c|c|c|}
\hline Platform & PowerBiofilm & QuickGene & Maxwell \\
\hline Ease of operation & Manual & Semi-automated & Automated \\
\hline Dedicated instrument & No & QuickGene-Mini80 & Maxwell 16 \\
\hline $\operatorname{Cost}^{a}$ & & $\$ 1500$ & $\$ 25000$ \\
\hline \multicolumn{4}{|l|}{ Processing steps } \\
\hline Sample preparation & Manual & Manual & Manual \\
\hline Cell lysis & Manual & Manual & Automated \\
\hline Inhibitor removal & Manual & Manual & Automated \\
\hline Nucleic acid mobilization & Manual & Automated & Automated \\
\hline $3 \times$ Washes & Manual & Automated & Automated \\
\hline Elution & Manual & Automated & Automated \\
\hline Total time & $120 \min (n=10)$ & $60 \min (n=8)$ & $45 \min (n=16)$ \\
\hline \multicolumn{4}{|l|}{ Additional equipment } \\
\hline Microcentrifuge & Yes & Yes & No \\
\hline Incubator $\left(>55^{\circ} \mathrm{C}\right)$ & Yes & Yes & No \\
\hline Physical lysis equipment ${ }^{b}$ & Yes & Yes & No \\
\hline Refrigerator $\left(4^{\circ} \mathrm{C}\right)$ & Yes & No & No \\
\hline \multicolumn{4}{|l|}{ Consumable supplies } \\
\hline Cost (per sample) & $\$ 6.50$ & $\$ 2.60$ & $\$ 6.33$ \\
\hline
\end{tabular}

${ }^{\mathrm{a}}$ Approximate list price at time of purchase.

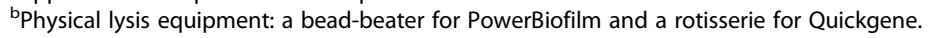


Maxwell ${ }^{\circledR} 16$ (Promega, Madison, WI) platforms. Both systems were designed to extract nucleic acids from various tissues and cell types in clinical labs (Affolabi et al. 2012) and both systems have proven successful for a wider variety of additional sample types including spores (Shipley et al. 2012), plant leaves, seeds, and fungi (Affolabi et al. 2012; Foley et al. 2011; Khokhar et al. 2011; Schagat et al. 2007). The manual kit, PowerBiofilm DNA Isolation Kit (MOBIO Laboratories, Carlsbad, CA), was designed to extract DNA from biofilm material and is representative of the kits widely used by environmental microbiologists (Ferrando and Tarlera 2009; McBeth et al. 2010). For the three test samples, we compared extraction platform ease of use and DNA yields. A series of PCR-based analyses was then used to assess DNA extract quality and effect on microbial community profiles.

\section{Materials and methods Pipeline biofilm samples}

Three samples scraped from the inner surface of oilfield pipelines (i.e. pigged pipeline material) were collected and stored at $-80^{\circ} \mathrm{C}$. Two of the samples, designated "A" and "B", originated from pipelines carrying produced water being returned to the formation to maintain pressure. A third sample, "C", originated from a pipeline as part of a seawater injection system for secondary oil recovery. Samples A and B contained crude oil, corrosion products such as iron sulfides and biofilm material (e.g. EPS). Sample C did not contain crude oil but did contain lesser quantities of corrosion products and biofilm material. For samples A, B, and C, DNA was extracted from ten aliquots (subsamples) for each extraction platform. For samples A and B $(40 \mathrm{ml})$, each was thawed at $4^{\circ} \mathrm{C}$, mixed, and ten replicate subsamples $(0.5 \mathrm{ml})$ were dispensed into $2 \mathrm{ml}$ conical screw-top tubes. Sample C (40 ml) was thawed, mixed, and ten replicate subsamples $(1 \mathrm{ml})$ were dispensed into $2 \mathrm{ml}$ conical tubes and concentrated by centrifugation for $5 \mathrm{~min}$ at $14000 \times \mathrm{g}$, removing $0.5 \mathrm{ml}$ of the supernatant and re-suspending the remaining volume. This concentration of biomass was deemed necessary for sample $C$, as initial studies revealed it contained $1 / 10^{\text {th }}$ of the biomass of samples $A$ or B (personal communication, Kathleen Duncan).

\section{MOBIO PowerBiofilm extraction platform}

The PowerBiofilm DNA Isolation Kit (MOBIO Laboratories) was used to manually extract DNA from ten replicate subsamples of samples A, B, and C according to the manufacturer's instructions. Specifically, the contents of a PowerBiofilm bead tube, and $350 \mu \mathrm{l}$ of buffer BF1 and $100 \mu \mathrm{l}$ of buffer BF2 were added to each sample tube. Samples were vortexed and incubated at $65^{\circ} \mathrm{C}$ for 5 min. Physical lysis of cell material was accomplished using the Mini-BeadBeater-16 (BioSpec Products, Bartlesville, OK) at 3450 oscillations/min for $2 \mathrm{~min}$. Samples were spun at $13000 \times g$ for $1 \mathrm{~min}$. Supernatants were transferred to fresh tubes and $200 \mu \mathrm{l}$ of buffer BF3 were added; samples were incubated at $4^{\circ} \mathrm{C}$ for $5 \mathrm{~min}$ and subsequently spun for $1 \mathrm{~min}$. Supernatants were transferred to fresh tubes and $900 \mu \mathrm{l}$ of buffer BF4 were added and samples mixed. Samples were loaded onto a PowerBiofilm spin filter column and spun for 1 min repeatedly until all sample was collected onto the filter. Filters were washed with $650 \mu \mathrm{l}$ of buffer BF5 followed by buffer BF6 and ended with a final spin for 2 min. DNA was eluted in 100 $\mu \mathrm{l}$ of buffer BF7 with a final spin for $1 \mathrm{~min}$.

\section{Fujifilm QuickGene-Mini80 extraction platform}

DNA was extracted from ten replicate subsamples of A, $\mathrm{B}$, and $\mathrm{C}$ using the QuickGene DNA Tissue Kit S with the semi-automated QuickGene-Mini80 instrument (Autogen/FujiFilm, Holliston, MA) following manufacturer's instructions. Cell lysis was facilitated by adding $180 \mu \mathrm{l}$ of Tissue lysis buffer (Autogen/FujiFilm) and $20 \mu \mathrm{l}$ Proteinase $\mathrm{K}$ to each sample tube and mixing with a Thermolyne LabQuake Rotisserie Tube Shaker (ThermoScientific/Barnstead, Waltham, MA) for $30 \mathrm{~min}$ at $55^{\circ} \mathrm{C}$. Samples were spun at $10000 \times g$ for $3 \mathrm{~min}$. The supernatants were transferred to a new tube and $20 \mu \mathrm{l}$ RNase A were added and incubated for $2 \mathrm{~min}$. Next, $180 \mu \mathrm{l}$ Lysis buffer and $240 \mu \mathrm{l}$ ethanol (>99\%) were added and the sample was vortexed for $15 \mathrm{~s}$. Samples were transferred to QuickGene cartridges and placed within the QuickGene Mini80 apparatus, and DNA binding, washing, and elution were accomplished through pressurization. DNA was eluted with $200 \mu \mathrm{l}$ Elution buffer.

\section{Promega Maxwell 16 extraction platform}

DNA was extracted from ten replicate subsamples of A, B, and $C$ using the automated Maxwell 16 Cell Total RNA Purification Kit with the Maxwell 16 Instrument (Promega) set to the LEV (low elution volume) configuration. Specifically, samples were loaded into the pre-dispensed reagent cartridges along with $400 \mu \mathrm{l}$ RNA lysis buffer and $400 \mu \mathrm{l}$ RNA dilution buffer. Elution tubes containing 100 $\mu \mathrm{l}$ nuclease-free water, plungers, and cartridges containing the sample and buffers were placed within the instrument and all subsequent steps were automated following the pre-programmed DNA extraction protocol. The DNAremoval steps of the Total RNA Purification Kit protocol were omitted to preserve the DNA (Promega Field Application Specialist, personal communication).

\section{Evaluation of extracted DNA yield}

DNA extracts from the subsamples were analyzed by gel electrophoresis and quantified using fluorometry to 
compare the reproducibility of extraction among replicate samples. To visualize the DNA fragment, $10 \mu \mathrm{l}$ of each extract was analyzed alongside $2 \mu \mathrm{l}$ of Lambda DNA/EcoRI+HindIII marker (ThermoFisherScientific/ Fermentas, GlenBurnie, MD) on a 1\% agarose gel (wt/vol) stained with $\mathrm{SYBR}^{\circledR}$ Safe (Invitrogen, Carlsbad, CA). Gels were visualized and the image captured using the Gel Logic 112 Imaging System and Molecular Imaging Software v5 (Carestream, WoodBridge, CT). DNA extracts were quantified using the Qubit 2.0 fluorometer with the dsDNA or RNA reagents according to the manufacturer's protocol (Invitrogen/Life Technologies, Carlsbad, CA). GraphPad Prism5 (GraphPad Software, San Diego, CA) was used to generate box-and-whisker plots to visualize the degree of variation in DNA yields among replicate extractions. Upper and lower whiskers illustrate the maximum and minimum DNA yields, respectively, and the median DNA yield separates the box into upper (75\%) and lower (25\%) quartiles.

For each of the three platforms, the ten subsample DNA extracts were pooled to generate DNA stocks for subsequent analyses to assess DNA extract quality and its effect on the microbial community structure, while minimizing the effect of small sample volumes. For each of the three samples A, B, and C, the total amount of DNA extracted from equivalent sample volumes for each platform was determined by multiplying the concentration of each of the ten subsample extractions by its elution volume and summing the products.

\section{Evaluation of extracted DNA quality using qPCR analysis}

DNA extraction quality was evaluated for PCR inhibition via amplification of the bacterial $16 \mathrm{~S}$ rRNA gene in undiluted versus diluted DNA extracts. Briefly, $30 \mu \mathrm{l}$ reactions contained $15 \mu \mathrm{l} 2 \times \mathrm{SYBR}^{\circledR}$ Green PCR Master Mix (Life Technologies, Carlsbad, CA), 0.5 M betaine (N,N, N-Trimethylglycine) (Sigma-Aldrich, St Louis, MO), $250 \mathrm{nM}$ of the primer $27 \mathrm{f}$ ( $5^{\prime}$-AGAGTTTGATCCTGGCT CAG) and $125 \mathrm{nM}$ of the primer $338 \mathrm{r}\left(5^{\prime}-\mathrm{TG}\right.$ CTGCCTCCCGTAGGAGT) as described in Stevenson et al. (2011). Thermal cycling, data acquisition and analyses were carried out with the StepOnePlus ${ }^{\mathrm{TM}}$ Real-Time PCR System and StepOne Software v2.1 (Life Technologies). Cycling conditions were: $95^{\circ} \mathrm{C}$ for $10 \mathrm{~min}$ followed by 40 cycles of $95^{\circ} \mathrm{C}$ for $30 \mathrm{~s}, 55^{\circ} \mathrm{C}$ for $45 \mathrm{~s}, 72^{\circ} \mathrm{C}$ for $45 \mathrm{~s}$, and ended with a melt curve stage of $95^{\circ} \mathrm{C}$ for $15 \mathrm{~s}$, $60^{\circ} \mathrm{C}$ for $1 \mathrm{~min}$, and $95^{\circ} \mathrm{C}$ for $15 \mathrm{~s}$. Image capture was at $72^{\circ} \mathrm{C}$. DNA was assayed in triplicate at undiluted, 1:10, and 1:100 dilutions. A 10-fold dilution series of a control plasmid was assayed in duplicate and spanned $10^{3}$ to $10^{9}$ copies. Molar concentrations were converted into $16 \mathrm{~S}$ copies based on the following assumptions: the average molecular mass of a double strand DNA base pair (bp) is $6.6 \times 10^{11} \mathrm{ng} \mathrm{mol}^{-1}$, Avogadro's number of copies $\mathrm{mol}^{-1}$ is $6.02 \times 10^{23}$ (McKew and Smith 2010):

$$
\begin{aligned}
& \text { Copies }= \\
& \frac{\text { concentration }(\mathrm{ng} \text { per } \mu \mathrm{l}) \times 6.02 \times 10^{23}(\text { copies per mol })}{\text { length }(\mathrm{bp}) \times 6.6 \times 10^{11}(\mathrm{ng} \text { per mol })}
\end{aligned}
$$

Evaluation of the influence of DNA extraction platform on microbial community composition using denaturing gradient gel electrophoresis (DGGE)

A DGGE analysis of amplified bacterial $16 \mathrm{~S}$ rRNA genes was used to evaluate potential biases in cell lysis between extraction platforms. Briefly, $2 \mu \mathrm{l}$ of DNA were amplified by end-point PCR in $25 \mu$ l reactions. Each reaction contained: $0.625 \mathrm{U}$ DreamTaq ${ }^{\mathrm{TM}}$ polymerase (Fermentas, Glen Burnie, MD), $0.2 \mathrm{mM}$ dNTP mixture, $0.5 \mathrm{M}$ betaine, $1 \times$ Dream Taq Buffer (Fermentas), and $100 \mathrm{nM}$ each of forward primer GM5F (5'-CCTACGGGAGGCAG CAG) containing the GC clamp on the 5 '-end and reverse primer D907R (5'-CCCCGTCAATTCCTTTGAGTTT) (Santegoeds et al. 1999). Thermal cycling was carried out with a TC-512 thermal cycler (Techne, Burlington, NJ) using a touchdown PCR program from $65^{\circ} \mathrm{C}$ to $55^{\circ} \mathrm{C}$. Conditions were $94^{\circ} \mathrm{C}$ for $4 \mathrm{~min}$, followed by 2 cycles each of $94^{\circ} \mathrm{C}$ for $1 \mathrm{~min}, \mathrm{~N}^{\circ} \mathrm{C}$ for $1 \mathrm{~min}$, and $72^{\circ} \mathrm{C}$ for $1 \mathrm{~min}$, where $\mathrm{N}^{\circ} \mathrm{C}$ dropped $1^{\circ} \mathrm{C}$ from $65^{\circ} \mathrm{C}$ to $55^{\circ} \mathrm{C}$, followed by 15 cycles at the $55^{\circ} \mathrm{C}$ annealing temperature and a final extension at $72^{\circ} \mathrm{C}$ for $10 \mathrm{~min}$. For bacterial community analysis, $15 \mu \mathrm{l}$ of each reaction was resolved on a $6 \%$ polyacrylamide, urea and formamide $40-60 \%$ denaturing gradient gel (100\% denaturant $=7 \mathrm{M}$ Urea and 40\% formamide) (Muyzer et al. 1993) and run at $65 \mathrm{~V}$ for $16 \mathrm{~h}$ at $60^{\circ} \mathrm{C}$. The gel was stained for $15 \mathrm{~min}$ in SYBR Safe (at $25 \mu \mathrm{l}$ per $250 \mathrm{ml}$ ) and visualized as described above.

\section{Identification of microbial community composition among DNA extracts using high throughput sequencing of 16S rRNA gene libraries}

To identify major bacterial taxa in samples A, B, and C DNA extracts, bacterial 16S rRNA gene libraries were generated from each extraction method modeled after the approach used by Wawrik et al. (2011). For each sample, triplicate $50 \mu \mathrm{l}$ reactions contained $5 \mu \mathrm{l}$ to $10 \mu \mathrm{l}$ DNA, $1.25 \mathrm{U}$ DreamTaq polymerase, $0.2 \mathrm{mM}$ dNTP mixture, $0.5 \mathrm{M}$ betaine, 1xDreamTaq Buffer (Fermentas), $250 \mathrm{nM} 27 \mathrm{f}$ and $125 \mathrm{nM} 338 \mathrm{r}$ primers. Thermal cycling was carried out on a TC-512 thermal cycler (Techne) with the following conditions: $96^{\circ} \mathrm{C}$ for $3 \mathrm{~min} ; 30$ cycles of $96^{\circ} \mathrm{C}$ for $30 \mathrm{~s}, 55^{\circ} \mathrm{C}$ for $45 \mathrm{~s}, 72^{\circ} \mathrm{C}$ for $45 \mathrm{~s}$; and a final extension at $72^{\circ} \mathrm{C}$ for $10 \mathrm{~min}$. Triplicate reactions were pooled and purified using the Wizard PCR Preps DNA Purification System (Promega). From each of the purified PCRs, $5 \mu \mathrm{l}$ was added to a second PCR containing 
barcoded PCR primers TiA-8nt-CA-27f (5'-CCAT CTCATCCCTGCGTGTCTCCGACTCAGxxxxxxxxCAA GAGTTTGATCCTGG CTCAG) and TiB-CA-338r (5'CCTATCCCCTGTGTGCCTTGGCAGTCTCAGCA TG CTGCCTCCCGTAGGAGT) for multiplexed pyrosequencing as described by Hamady et al. (2008). Each sample received a different tagged forward primer, containing a specific 8 nt 'barcode' sequence (designated by $\mathrm{x}$ ), and samples were 'tagged' by re-amplification for six cycles. Barcodes are listed in Additional file 1: Table S1. The efficacy of the tagging reaction was confirmed by gel electrophoresis. Tagged PCR products were pooled in equimolar amounts and sequenced on a GS-FLX sequencer using the Titanium chemistry at (University of Oklahoma's Advanced Center for Genome Technology 2012).

The bacterial 16S rRNA gene libraries were analyzed using the bioinformatics software package, mothur ver1.24 (Schloss et al. 2009). An implementation of the Amplicon Noise algorithm was used to reduce the sequencing error incurred with pyrosequencing (Quince et al. 2011). Sequences were binned by barcode and screened to remove those containing errors in the forward primer or barcode. Unique sequences were trimmed to overlap a minimum of 200 base pairs and aligned against the SILVA reference alignment database (Pruesse et al. 2007) using the NAST-aligner (DeSantis et al. 2006). Sequences were pre-clustered using a single linkage algorithm (Huse et al. 2010) to reduce the number of spurious operational taxonomic units (OTUs) that would result from pyrosequencing errors, and subsequently screened for chimeras using UChime (Edgar et al. 2011). A distance matrix was generated and used to cluster sequences into OTUs at a $97 \%$ similarity level using the furthest neighbor algorithm. A representative sequence from each OTU was assigned a taxonomic classification based on the Ribosomal Database Project's naïve Bayesian classifier (Wang et al. 2007) at an $80 \%$ confidence threshold; and all richness and diversity measurements were calculated using the mothur software package based on a random subsampling subset of 1958 sequences to equal the number of reads in the smallest library. Using the generated distance matrix, an analysis of molecular variance (AMOVA) was used to determine if the observed differences in microbial diversity between sample groups or extraction methods was significantly different (Schloss 2008; Schloss and Handelsman 2008). Sequences were deposited in the short read archive of GenBank [GenBank: SRA052225].

\section{Results}

\section{DNA extraction platform ease of use and cost} considerations

The ease of use and cost parameters for the three extraction platforms are compared in Table 1. For PowerBiofilm, all steps from sample preparation to DNA elution were manual and additional equipment for sample processing included a microcentrifuge, bead-beater, incubator, and refrigerator. With multiple centrifugations, sample transfers, and incubation steps, the total processing time was approximately $120 \mathrm{~min}$ for ten samples. For the QuickGene Mini-80, initial sample processing steps were similar to that of PowerBiofilm with centrifugations and incubations for sample preparation and cell lysis, but DNA binding, washes, and elution were streamlined to process eight samples in parallel using pressure filtration technology. The total processing time was approximately $60 \mathrm{~min}$, which included a $30 \mathrm{~min}$ incubation step for cell lysis. The Maxwell 16 platform required the least manual manipulation, with the transfer of sample plus lysis and dilution buffers to pre-filled reagent cartridges. The only other manual steps required for extraction set up were the addition of elution buffer, collection tubes and plungers into the cartridge-holder. All subsequent steps from cell lysis to nucleic acid elution were fully automated using pre-programmed settings and up to 16 samples could be processed in parallel. Extraction times for the two more automated platforms were less than half that as the manual method. Additional equipment requirements for sample processing were similar for PowerBiofilm and QuickGene; both required a microcentrifuge and incubator for processing steps as well as equipment for cell lysis. No additional equipment was necessary for the Maxwell 16 platform aside from the instrument itself. With regard to price per sample, consumable supplies for PowerBiofilm and Maxwell were similarly priced, whereas QuickGene was approximately one-third less (Table 1).

\section{Comparison of DNA yield between extraction platforms from equivalent starting sample volumes}

Biofilm material scraped from the inner surface of three separate oil pipelines were initially extracted as ten subsamples to compare extraction reproducibility among replicate samples. The DNA fragment was visualized by gel electrophoresis and the gel images for sample A extracts are shown for a visual comparison between the three platforms (Figure 1). The PowerBiofilm method (P) extracted appreciable amounts of DNA from the ten subsamples, but DNA yields varied widely among them (Figure 1a). This result indicated a low consistency in extraction among replicate samples. By contrast, the QuickGene platform demonstrated more uniformity among subsamples (Figure 1, compare panel a to b), as did the Maxwell (Figure 1, compare panel a to c). RNA was also extracted using the Maxwell system, and was visible as a low molecular weight band (Figure 1c).

DNA yields were estimated for each extraction using Qubit fluorometry and box-plots were used to illustrate the level of variability in DNA yields among the ten 


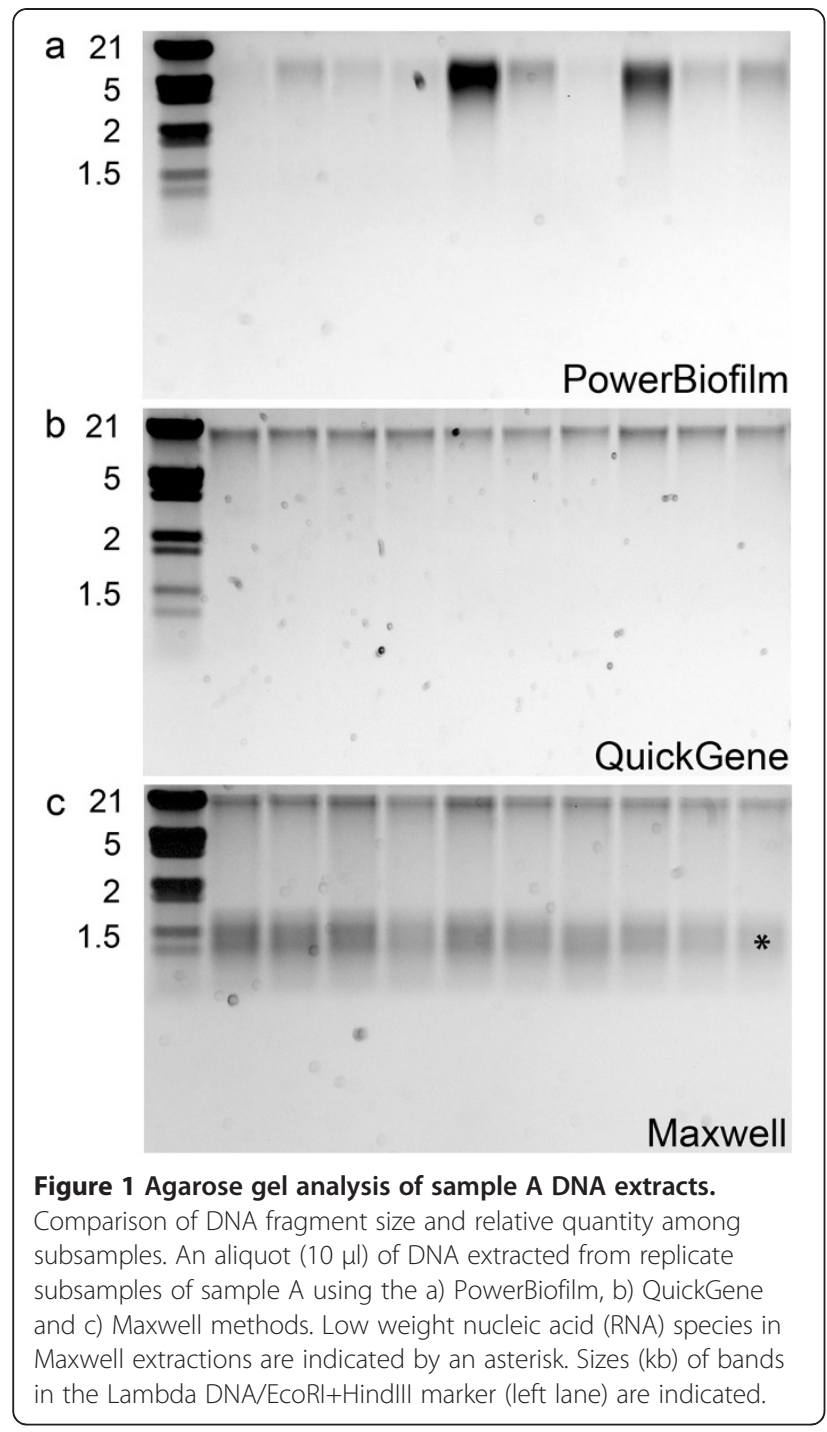

replicate DNA extracts (Figure 2). For sample A PowerBiofilm extracts, DNA yields ranged more than 10-fold from $0.06 \mu \mathrm{g}$ to $1.17 \mu \mathrm{g}$, with the median yield at $0.17 \mu \mathrm{g}$ (Figure 2a). For QuickGene and Maxwell extracts, median values were higher than PowerBiofilm and DNA yields were more consistent among the replicates. For samples B and C, distances between upper and lower whiskers (i.e. maximum and minimum yields, respectively) were closest among replicates for the Maxwell and PowerBiofilm extracts, respectively (Figures 2b and 2c). Subsequently, the ten replicate DNA extracts from each platform were pooled to compare the total DNA yields from equivalent starting sample volumes. The total amount of DNA extracted from $5 \mathrm{ml}$ of sample A was approximately $3.37 \mu \mathrm{g}$ using PowerBiofilm. Yields were higher for QuickGene and Maxwell at $8.01 \mu \mathrm{g}$ and $6.01 \mu \mathrm{g}$, respectively. For sample B, the automated platforms also increased DNA yields from $0.94 \mu \mathrm{g}$ (PowerBiofilm) to $12.56 \mu \mathrm{g}$ and $5.80 \mu \mathrm{g}$ for Maxwell and
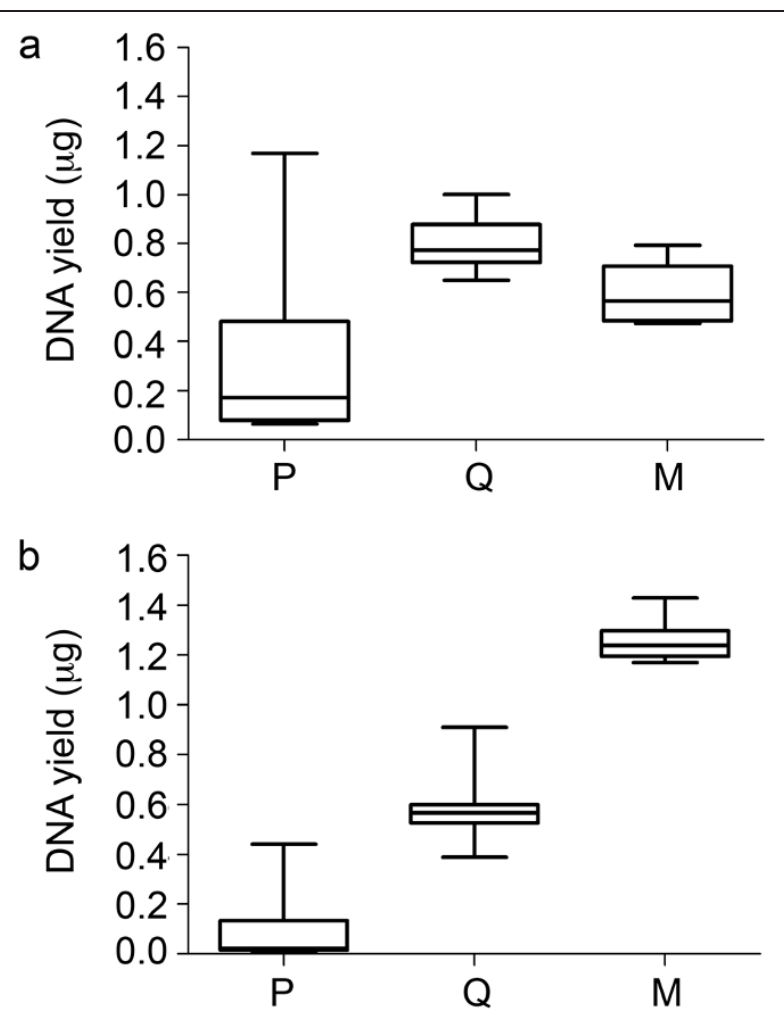

C

0.16

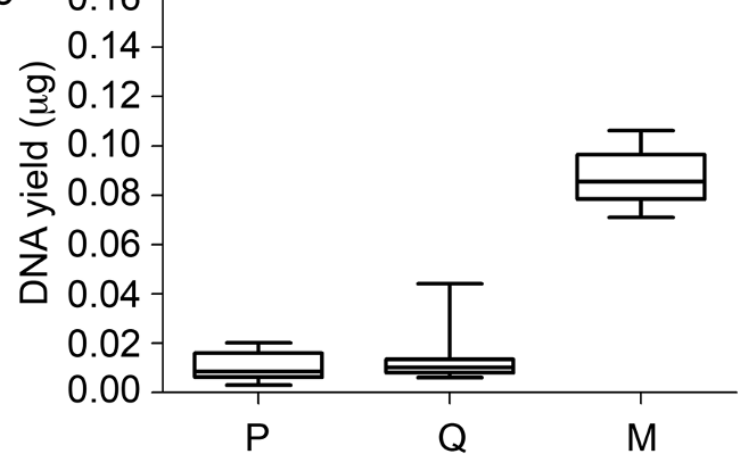

Figure 2 Illustration of DNA extraction variability among replicate subsamples. Box and whisker plots of replicate extractions ( $(=10)$ for $\mathbf{a})$ sample $A, \mathbf{b})$ sample $B$, and $\mathbf{c}$ ) sample $C$ using PowerBiofilm (P), QuickGene (Q) and Maxwell (M) methods. The lower and upper whiskers illustrate minimum and maximum yields, respectively and the median yield separates the box into upper and lower quartiles.

QuickGene, respectively. Next, DNA yields from the lower biomass sample $\mathrm{C}$ extractions were compared. From $10 \mathrm{ml}$ of sample C, DNA yields were comparable for PowerBiofilm and QuickGene at $100 \mathrm{ng}$ and $130 \mathrm{ng}$, respectively, however DNA yield was increased by almost ten-fold (870 ng) using the Maxwell platform. Together, these data demonstrated that the Maxwell platform could increase the DNA yields from both the high- and lower-biomass samples. QuickGene could also increase yields from samples A and B but had a 
negligible effect on the low-biomass sample C. Together, these results demonstrated that more automated platforms extracted higher DNA yields than the manual approach from equivalent starting sample volumes.

\section{Assessment of extracted DNA quality (i.e. PCR inhibition) by qPCR amplification in undiluted and diluted DNA extracts}

DNA extract quality was evaluated for PCR inhibition via amplification of the V1-V2 region of the bacterial 16S rRNA gene in undiluted versus diluted (1:10 and 1:100) DNA extracts (Table 2). The rationale being that gene copy estimates per $\mathrm{ml}$ original sample would be higher using the diluted versus undiluted DNA extracts, as potential PCR inhibitors would be diluted out (Stults 2001). Estimates of gene copies per $\mathrm{ml}$ original sample for sample A were $\sim 10^{9}$ copies per $\mathrm{ml}$, with PowerBiofilm and QuickGene setting the lower and upper limits, respectively. For sample B, PowerBiofilm estimates were $10^{8}$ copies per $\mathrm{ml}$, whereas the two more automated extractions both showed $\sim 10^{9}$ copies per ml. For sample $\mathrm{C}$, estimated numbers of gene copies per $\mathrm{ml}$ increased from $\sim 10^{6}$ for PowerBiofilm and QuickGene to $\sim 10^{8}$ for Maxwell. While there was some variation between estimates for a given sample among dilutions, 16S rRNA gene estimates mirrored the DNA quantification data with higher estimates from those with higher DNA yields. Importantly, gene estimates were not higher in the undiluted versus diluted DNA samples suggesting that PCR inhibitors were effectively removed by all three extraction platforms and did not interfere with

Table 2 Evaluation of PCR inhibition via bacterial 16S rRNA gene amplification in undiluted (1x) versus diluted DNA extracts ${ }^{a}$

\begin{tabular}{|c|c|c|c|}
\hline & $1 x^{b}$ & $1: 10 x^{b}$ & $1: 100 x^{c}$ \\
\hline \multicolumn{4}{|c|}{ Sample A } \\
\hline$P$ & $2.03 \pm 0.15 \times 10^{9}$ & $2.07 \pm 0.02 \times 10^{9}$ & $1.32 \pm 0.07 \times 10^{9}$ \\
\hline $\mathbf{Q}$ & $6.26 \pm 0.57 \times 10^{9}$ & $6.06 \pm 0.13 \times 10^{9}$ & $2.88 \pm 0.04 \times 10^{9}$ \\
\hline$M$ & $2.55 \pm 0.26 \times 10^{9}$ & $2.38 \pm 0.10 \times 10^{9}$ & $2.46 \pm 0.08 \times 10^{9}$ \\
\hline \multicolumn{4}{|c|}{ Sample B } \\
\hline$P$ & $8.44 \pm 0.17 \times 10^{8}$ & $7.33 \pm 0.10 \times 10^{8}$ & $5.79 \pm 0.10 \times 10^{8}$ \\
\hline $\mathbf{Q}$ & $6.34 \pm 0.56 \times 10^{9}$ & $6.32 \pm 0.13 \times 10^{9}$ & $3.72 \pm 0.19 \times 10^{9}$ \\
\hline$M$ & $4.70 \pm 0.08 \times 10^{9}$ & $5.16 \pm 0.20 \times 10^{9}$ & $3.95 \pm 0.23 \times 10^{9}$ \\
\hline \multicolumn{4}{|c|}{ Sample C } \\
\hline$P$ & $6.28 \pm 0.43 \times 10^{6}$ & $6.83 \pm 0.85 \times 10^{6}$ & $7.48 \pm 0.52 \times 10^{6}$ \\
\hline $\mathbf{Q}$ & $9.26 \pm 5.48 \times 10^{6}$ & $9.59 \pm 0.28 \times 10^{6}$ & $8.83 \pm 0.18 \times 10^{6}$ \\
\hline$M$ & $1.74 \pm 0.04 \times 10^{8}$ & $1.14 \pm 0.05 \times 10^{8}$ & $1.15 \pm 0.01 \times 10^{8}$ \\
\hline
\end{tabular}

${ }^{a}$ Data shown are mean values $(n=3)$ and standard deviations of 16S rRNA gene copies per $\mathrm{ml}$ original sample.

${ }^{\mathrm{b}}$ Standard curve: $\mathrm{m}=-3.67 ; \mathrm{y}$-int $=41.61 ; \mathrm{R}^{2}=0.99 ; \mathrm{Eff}=87.1 \%$.

'Standard curve: $m=-3.59 ; y$-int $=41.15 ; R^{2}=0.99 ; E f f=89.7 \%$. amplification of the bacterial 16S rRNA gene in the undiluted DNA extracts.

\section{Effect of DNA extraction platform on bacterial community composition by DGGE analysis}

DNA extracts were further evaluated by amplification of the V3-V4 region of the bacterial 16R rRNA gene using end-point PCR. A DGGE analysis of these PCR products was evaluated to ask if the extraction platform influenced the bacterial community profile, as extraction method bias is well documented in the literature for difficult sample types, such as those containing grampositive bacteria (Frostegard et al. 1999; Stach et al. 2001). While some variation in band intensity was observed, the overall banding patterns were similar among the three extraction methods for the same sample (Figure 3). These results suggest that the more automated extraction platforms lysed a greater proportion of cells from equivalent sample volumes rather than extracting DNA from group(s) of bacteria that were not lysed using PowerBiofilm.

\section{Identification of bacterial communities in DNA extracts using 454 pyrosequencing}

To identify the major bacterial taxa present in the three samples, 454 pyrosequencing libraries of the V1-V2

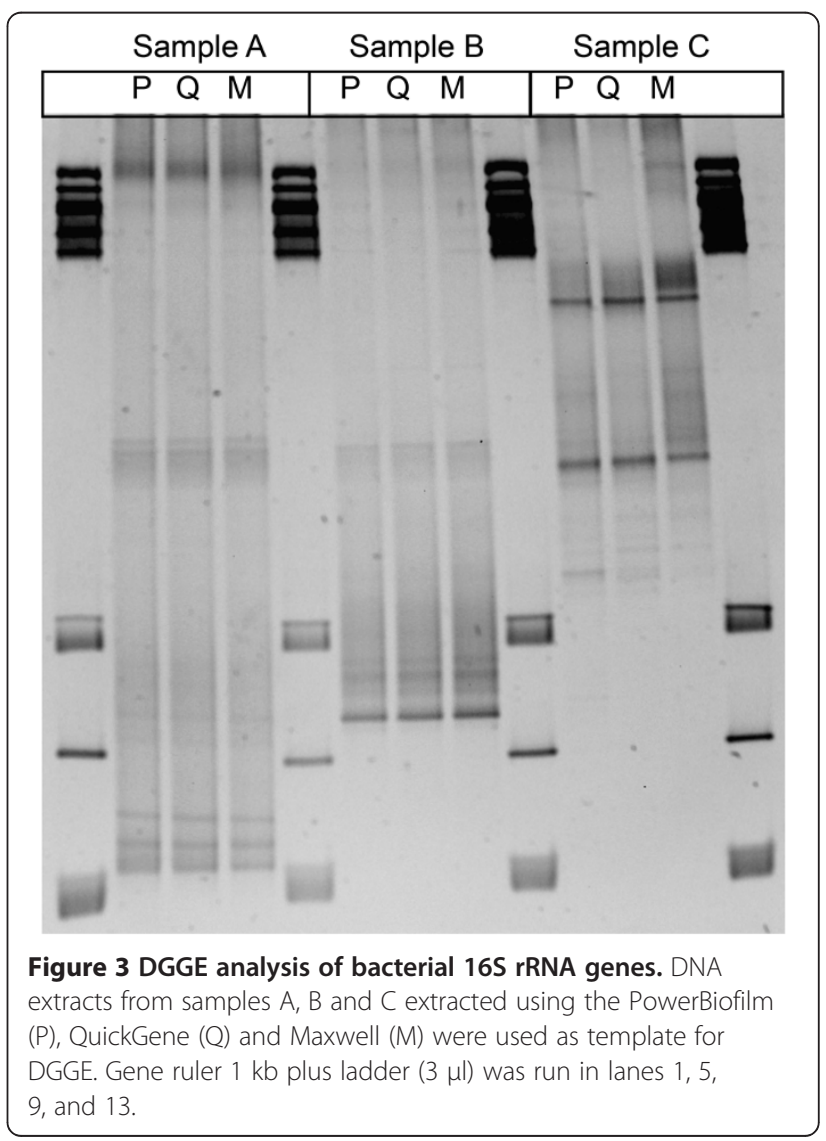


region of $16 \mathrm{~S}$ rRNA gene were generated (Figure 4). The number of sequences analyzed per $16 \mathrm{~S}$ gene library were: 11907 (P), $12076(\mathrm{Q})$, and 1050 (M) for sample A; 9754 (P) $8186(\mathrm{Q})$ and 12634 (M) for sample B; and 11319 (P), 14705 (Q), and 13175 (M) for sample C. Although library sizes varied considerably, especially for sample A, the proportion of sequences that classified to the same taxonomic groups (at 97\% similarity) was comparable among the DNA extracts (Figure 4). Furthermore, bacterial composition was very different between the three samples. For sample A, dominant phyla were gram-positive members of the Firmicutes (48-56\%), and to a lesser extent Thermotogae (22-36\%), Thermodesulfobacteria (6-16\%) and Synergistetes (6-9\%) (Figure 4a). The dominance of gram-positive Firmicutes in all three sample A extracts demonstrated that the three platforms were all capable of lysing these harder-to-lyse microorganisms. For sample B libraries, members of the phylum Synergistetes (46-47\%) and the class Deltaproteobacteria
(50-52\%) were equally dominant among extracts, with minor representation by Thermatogae (0.7-2.0\%) (Figure 4b). DNA extracts from the seawater-carrying pipeline sample $C$ appeared more diverse than samples $\mathrm{A}$ and $\mathrm{B}$, with dominant taxonomic groups that included members of the Gammaproteobacteria (49-56\%), Alphaproteobacteria (7-10\%), and Bacteroidetes (19-33\%). Less abundant representation by Epsilonproteobacteria and Fusobacteria (2-3\%) and the minor group of grampositive Actinobacteria (0.1-1.8\%) was also observed (Figure 4c). An AMOVA performed on a random subsample (1050 sequences) from each library demonstrated that samples clustered together regardless of extraction method and were significantly different from one another $(p<0.001)$ (Figure $4 d$ ). These data support the conclusions drawn from the DGGE analysis demonstrating: 1) microbial communities of the three samples differed from one another and 2) bacterial composition for a given sample was comparable among the three
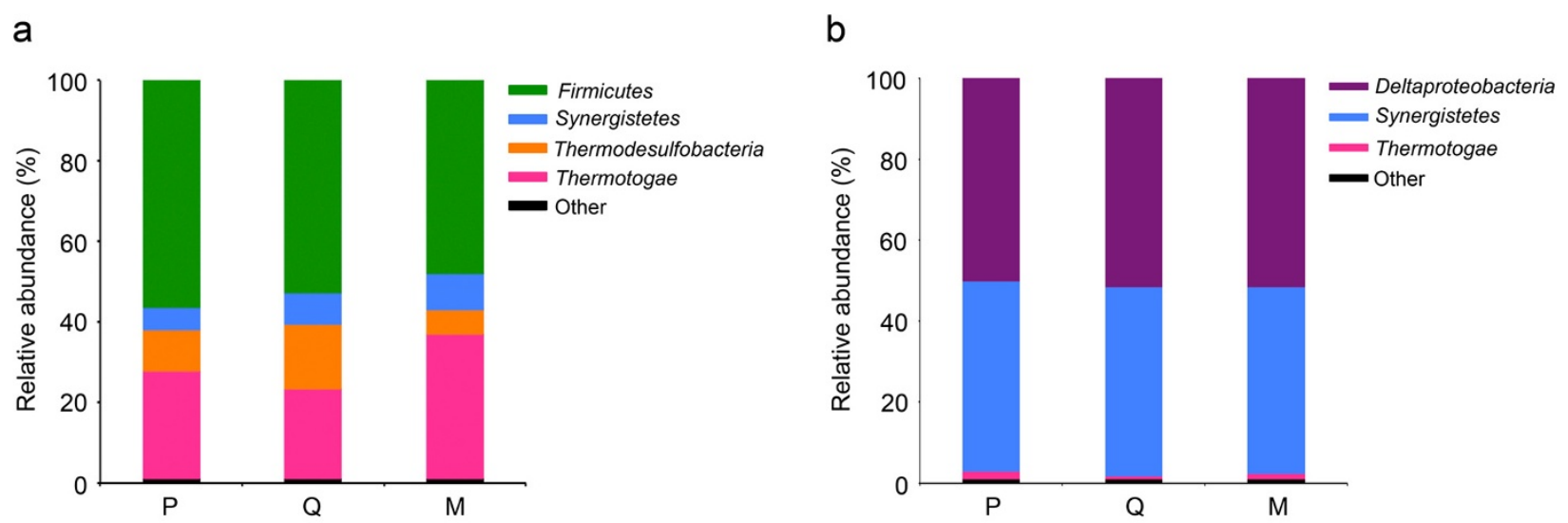

C

d
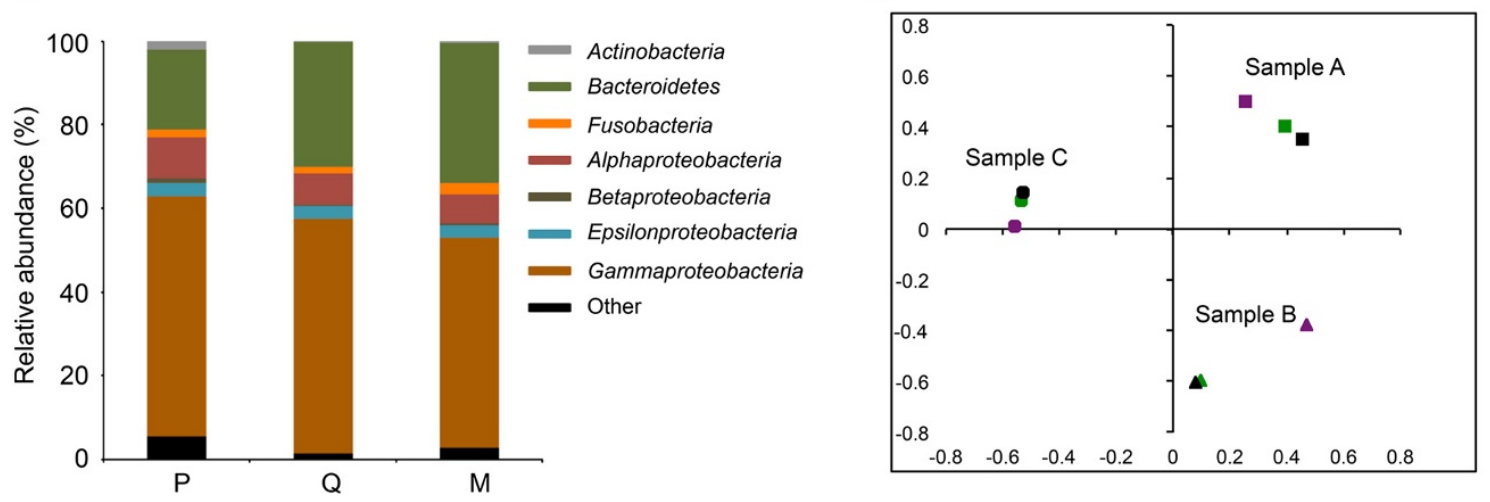

Figure 4 Comparison of microbial communities based on 16S rRNA gene sequencing. Relative abundance of bacterial phyla (class for Proteobacteria) from DNA extracted from a) sample $A, \mathbf{b}$ ) sample B and c) sample C using the PowerBiofilm (P), QuickGene (Q) and Maxwell (M) extraction methods. Unclassified sequences and phyla (or class for Proteobacteria) with membership $<1 \%$ of total sequences were pooled into the classification labeled "Other". d) Non-metric multidimensional scaling (NMDS) plot based on $\theta_{Y c}$ distances between libraries extracted using the PowerBiofilm (purple), QuickGene (green) and Maxwell (black) methods from Sample A (squares), B (triangles) and C (circles). AMOVA: $p<0.001$ 
extraction methods. Furthermore, whether a dominant (sample A) or minor (sample C) group, gram-positive bacteria were detected by all three platforms with only minor variation between the three extraction methods.

Next, to rule out extraction bias as the sole source of variation observed between extraction platforms, technical replicates were compared (Figure 5, Additional file 1: Table S2). Sample A was chosen for this analysis, as a large proportion of its membership belongs to the grampositive Firmicutes (Figure 4a). Three replicates of the Maxwell and PowerBiofilm extractions were compared, as they represent the most and least automated platforms, respectively (Table 1 ). The six sample A libraries (three Maxwell replicates and three PowerBiofilm replicates) contained a total of 14806 sequences that clustered into 308 OTUs at 97\% similarity, 127 of which were singletons (i.e. OTU containing a single sequence). Analysis of a random number of sequences $(n=1958)$ from each library showed that although there was variation among all libraries (Additional file 1 Table S2) they were not significantly different from one another (AMOVA: $\mathrm{p}=0.106$ ). Furthermore, an analysis of the dominant phyla demonstrated that sequences from all replicates were classified as members of the same few genera: Thermacetogenium, Halolactibacillus, and Thermoanaerobacter for Firmicutes (phylum); Thermovirga for Synergistetes (phylum); Thermodesulfobacterium for Thermodesulfobacteria (phylum); and Kosmotoga, Thermotoga, and Thermosipho for Thermotogae (phylum). Approximately 99\% of the sequences were represented in both extraction methods. The $\sim 1 \%$ of sequences exclusive to one or the other were either unclassified or

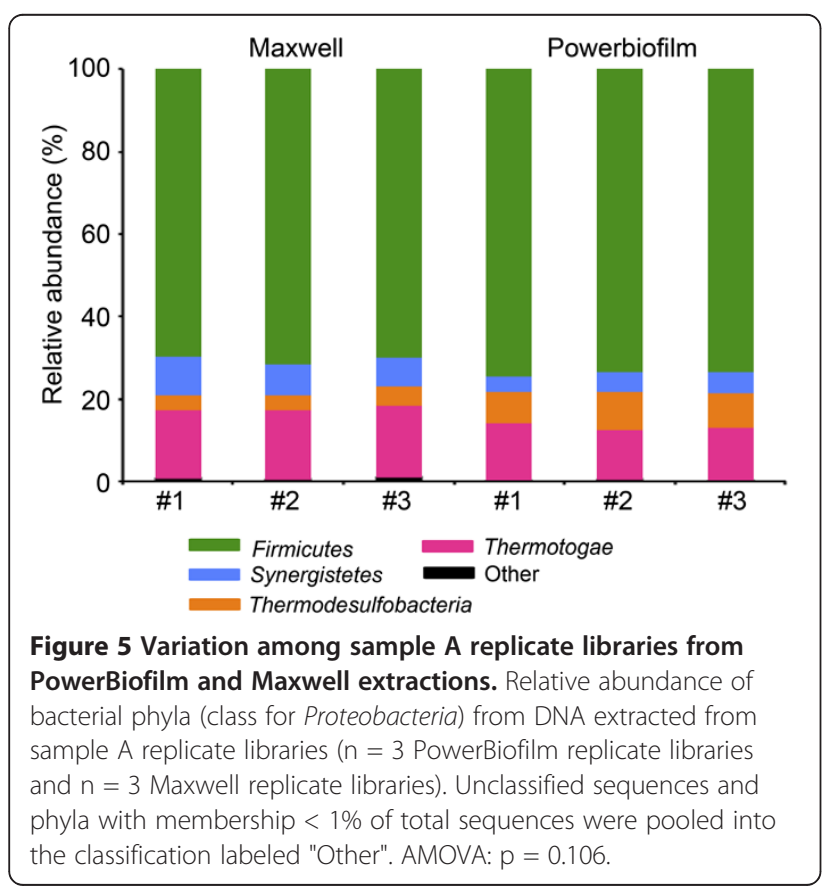

sequences present in only one of the three replicates for a given extraction method.

\section{Discussion}

In lieu of lengthy and potentially biased culturing methods, PCR-based analyses are an adequate and much less time-consuming alterative to monitoring microbial biofouling (Filion 2012). However, the interval between sample collection and analysis can influence the microbial community structure (Rochelle et al.1994; van der Kraan et al. 2010) leading to erroneous results and complicating the ability to correctly assess fouling severity. Commercially available kits yield high-quality nucleic acids, but time-consuming sample processing and the requirements for additional equipment largely limits their use to molecular biology labs. Therefore, more automated nucleic acid extraction platforms were evaluated for potential use in performing DNA extractions in remote areas or with limited laboratory facilities. Automated platforms provide several practical advantages: 1 ) the ability to process samples in remote locations, 2) onsite extractions bypass the shipment of potentially hazardous samples, 3) reducing the training needed for personnel conducting the nucleic acid extraction, and 4) reducing time to implement corrective measures. Findings presented here demonstrated that the more automated methods were successful in extracting DNA from both high- and lower-biomass biofilm samples scraped from the inner surface of oil pipelines and that all three extraction platforms produced high-quality DNA suitable for PCR-based analyses.

The PowerBiofilm extraction platform included repeated vortexing, sample transfers, centrifugations, incubations, and additional equipment needed for processing steps. Personnel with some molecular biology experience are best suited for this level of sample manipulation. In addition to the need for technical expertise, variability in extraction reproducibility among subsamples (Figure 1a) warranted the consideration of alternate extraction platforms. The QuickGene platform also required manual steps for sample preparation and cell lysis, but the QuickGene-Mini80 instrument streamlined the binding, washing and elution using pressure filtration and could process up to eight samples simultaneously. Both QuickGene and PowerBiofilm platforms use column chromatography for DNA capture. QuickGene provided greater reproducibility and higher DNA yields for the high biomass samples, but still required ancillary equipment for sample preparation. The Maxwell method provided the best overall performance in terms of the ease of use and DNA yields for both high- and lower-biomass samples. The Maxwell 16 instrument, with the footprint of a microwave oven, is readily transportable for use in the field and can 
processes 16 samples simultaneously. Sample processing was completely automated, requiring no ancillary equipment and only minimal technical experience was required. These properties make the Maxwell system a better choice for DNA extractions at remote locations for the sample types tested.

Estimates of $16 \mathrm{~S}$ rRNA gene copies per $\mathrm{ml}$ original sample corroborated the quantitative differences in DNA yields. Many variables between the three platforms could account for the differences in extraction efficiency. One variable that is correlated to efficiency is the format of the matrix used to bind DNA (Kephart et al. 2006). QuickGene utilizes a specialized high-capacity DNAbinding membrane $\sim 1 / 12.5$ the thickness of traditional glass membranes and the Maxwell uses silica-coated paramagnetic beads to bind nucleic acids. These beads are transferred to adjacent wells for washing and elution of DNA. The magnetic beads may have a greater binding-capacity or opportunity to bind DNA than the filter matrices used with the PowerBiofilm (or QuickGene) platform. The filter formats may also retain a greater amount of contaminating compounds, yet all downstream analyses indicated that the DNA from each method was of high quality. Differences in cell lysis between each extraction platform were identified as a potential concern, as differences in the community analysis may result if complete lysis was not achieved (Frostegård et al. 1999; Krsek and Wellington 1999). The PowerBiofilm and Maxwell platforms included physical disruption via bead-beating or plunging activity by a magnetic rod respectively, whereas lysis by the QuickGene platform was accomplished through sample rotation at elevated temperature. Both DGGE and pyrosequencing of PCRamplified 16S rRNA genes, however, showed that the structures of the microbial communities surveyed were minimally affected by the method of DNA extraction (Figures 3 through 5). Importantly, the three extraction platforms showed similar proportions in the dominant gram-positive Firmicutes in sample A (56\%-P, 53\%-Q $48 \%-\mathrm{M})$, demonstrating that these three extraction platforms were capable of lysing cells with tough cell walls, which may be present in other complex samples.

The conclusion drawn from pyrosequencing data was made with caution as variation between technical replicates, replicate samples, and identical samples from one sequencing run to another has been documented (Zhou et al. 2011 and Schloss et al. 2011). With the number of singletons (single sequence-containing OTUs) ranging from 12 to 33 for each sample A replicate library, the variation observed for the OTU analysis was expected, as was that observed between the separate sequencing runs for the single (Figure 4) versus replicate (Figure 5) sample A analyses (i.e. gram-positive Firmicutes remained dominant at $50-60 \%$ and $70-75 \%$, respectively).
Therefore, while biases between extraction methods are noted in the literature (Stach et al. 2001), the variation observed in 454 pyrosequencing studies presented here may be primarily the result of variation arising during post-nucleic acid extraction processes (Schloss et al. 2011; Zhou et al. 2011).

The Promega Maxwell 16 platform's portability and ease of use make it an attractive alternative to manual extractions if space is a limitation. The Maxwell 16 has several advantages over the Powerbiofilm and QuickGene Mini-80 platforms. First, the Maxwell 16 requires no additional equipment for sample processing, resulting in minimal sample handling. Second, the small size allows transport for use in mobile labs, where samples taken from remote sites could be processed within hours of procurement. Third, up to 16 samples are ready for PCR-based analyses within an hour of processing ensuring that shifts in bacterial communities are minimal. We conclude that the QuickGene and Maxwell platforms are examples of suitable alternatives for molecular analysis of microbial biofouling, and that automated DNA extraction platforms from a variety of manufacturers may facilitate microbial contaminant assessment in many industrial settings.

\section{Additional file}

Additional file 1: Table S1.doc List of 8 nt barcodes for 454

pyrosequencing. Barcodes for each 454 pyrosequencing library.

Table S2.doc Measures of alpha diversity for each PowerBiofilm and Maxwell replicate library. Alpha diversity matrices for sample A replicate libraries.

\section{Competing interests}

The authors declare that they have no competing interests. None of the authors are employed by or have any financial stake in any of the companies represented in this manuscript aside from the loan of equipment for demonstration comparisons.

\section{Acknowledgements}

We gratefully acknowledge support from the University of Oklahoma Biocorrosion Research Center Consortium sponsored by ConocoPhillips, grant SRA FY10-ORA3-24. The authors would also like to thank Dr. Fares Najar for technical assistance with submitting libraries to GenBank. The conclusions expressed in this paper are those of the authors and not necessarily shared by the Biocorrosion Center or ConocoPhillips. We thank the Promega Corporation for loan of the Maxwell-16 instrument and FujiFilm for the QuickGene Mini80 instrument.

\section{Author details}

${ }^{1}$ The Department of Microbiology and Plant Biology, University of Oklahoma, 770 Van Vleet Oval GLCH \#136, Norman, OK 73019, USA. University of Oklahoma Biocorrosion Center, Norman, OK 73019, USA. ${ }^{3}$ The Institute for Energy and the Environment, University of Oklahoma, 100 E. Boyd Street, Norman, OK 73019, USA.

Received: 9 November 2012 Accepted: 16 November 2012 Published: 20 November 2012

\section{References}

University of Oklahoma's Advanced Center for Genome Technology (2012), http://www.genome.ou.edu. Accessed 07 November 2012 
Affolabi D, Sanoussi N, Vandelannoote K, Odoun M, Faïhun F, Sopoh G, Anagonou S, Portaels F, Eddyani M (2012) Effects of decontamination, DNA extraction, and amplification procedures on the molecular diagnosis of Mycobacterium ulcerans disease (Buruli ulcer). J Clin Microbiol 50(4):1195-1198

Bixler GD, Bhushan B (2012) Biofouling: lessons from nature. Philos Transact A Math Phys Eng Sci 370:2381-2417

DeSantis TZ Jr, Hugenholtz P, Keller K, Brodie EL, Larsen N, Piceno YM, Phan R, Andersen GL (2006) NAST: a multiple sequence alignment server for comparative analysis of 165 rRNA genes. Nucleic Acids Res. doi:10.1093/nar/ gk1244

Edgar RC, Haas BJ, Clemente JC, Quince C, Knight R (2011) UCHIME improves sensitivity and speed of chimera detection. Bioinformatics 27(16):2194-2200

Ferrando L, Tarlera S (2009) Activity and diversity of methanotrophs in the soilwater interface and rhizospheric soil from a flooded temperate rice field. J Appl Microbiol 106(1):306-316

Filion M (2012) Quantitative real-time PCR in Applied Microbiology. Caister Academic Press Place, Norfolk

Foley C, O'Farrelly C, Meade KG (2011) Technical note: Comparative analyses of the quality and yield of genomic DNA from invasive and noninvasive, automated and manual extraction methods. J Dairy Sci 94(6):3159-3165

Frostegård A, Courtois S, Ramisse V, Clerc S, Bernillon D, Le Gall F, Jeannin P, Nesme X, Simonet P (1999) Quantification of bias related to the extraction of DNA directly from soils. Appl Environ Microbiol 65(12):5409-5420

Hamady M, Walker JJ, Harris JK, Gold NJ, Knight R (2008) Error-correcting barcoded primers for pyrosequencing hundreds of samples in multiplex. Nat Methods 5(3):235-237

Huse SM, Welch DM, Morrison HG, Sogin ML (2010) Ironing out the wrinkles in the rare biosphere through improved OTU clustering. Environ Microbiol 12 (7):1889-1898

Kephart D, Krueger S, Grunst T, Shenoi H (2006) Introducing the Maxwell 16 instrument: a simple, robust and flexible tool for DNA Purification., , Promega Notes 92:20-23. Available via http://www.promega.com/resources/articles/ pubhub/promega-notes-2006/introducing-the-maxwell-16-instrument-asimple-robust-and-flexible-tool-for-dna-purification document. Accessed 07 November 2012

Khokhar SK, Mitui M, Leos NK, Rogers BB, Park JY (2011) Evaluation of Maxwell ${ }^{\mathrm{B}}$ 16 for automated DNA extraction from whole blood and formalin-fixed paraffin embedded (FFPE) tissue. Clin Chem Lab Med 50(2):267-272

Krsek M, Wellington EM (1999) Comparison of different methods for the isolation and purification of total community DNA from soil. J Microbiol Methods 39 (1):1-16

McBeth JM, Little BJ, Ray RI, Farrar KM, Emerson D (2010) Neutrophilic ironoxidizing "zetaproteobacteria" and mild steel corrosion in nearshore marine environments. Appl Environ Microbiol 77(4):1405-1412

McKew BA, Smith CJ (2010) Real-Time PCR approaches for analysis of hydrocarbon-degrading bacterial communities. In: Timmis KN (ed) Handbook of hydrocarbon and lipid microbiology. Springer-Verlag, Heidelberg

Murthy S, Venkatesan R (2009) Industrial biofilms and their control. In: Flemming HC, Murthy PS, Venkatesan R, Cooksey KC (eds) Marine and industrial biofouling. Springer-Verlag, Heidelberg

Muyzer G, de Waal EC, Uitterlinden AG (1993) Profiling of complex microbial populations by denaturing gradient gel electrophoresis analysis of polymerase chain reaction-amplified genes coding for 16S rRNA. Appl Environ Microbiol 59(3):695-700

Pruesse E, Quast C, Knittel K, Fuchs BM, Ludwig W, Peplies J, Glockner FO (2007) SILVA: a comprehensive online resource for quality checked and aligned ribosomal RNA sequence data compatible with ARB. Nucleic Acids Res 35 (21):7188-7196

Quarini J, Shire S (2007) A review of fluid-driven pipeline pigs and their applications. Proc IMEJ Proc Mech Eng 221:1-10. doi:10.1243/ 0954408JPME108

Quince C, Lanzen A, Davenport RJ, Turnbaugh PJ (2011) Removing noise from pyrosequenced amplicons. BMC Bioinforma 12:38-55

Rochelle PA, Cragg BA, Fry JC, Parkes RJ, Weightman AJ (1994) Effect of sample handling on estimation of bacterial diversity in marine sediments by $16 \mathrm{~S}$ rRNA gene sequence analysis. FEMS Microbiol Ecol 15:215-225

Santegoeds CM, Damgaard LR, Hesselink G, Zopfi J, Lens P, Muyzer G, de Beer D (1999) Distribution of sulfate-reducing and methanogenic bacteria in anaerobic aggregates determined by microsensor and molecular analysis. Appl Environ Microbiol 65(10):4618-4629
Schagat T, Koller S, Leone P, Cremonesi P, Bosetti A, Wieczorek D, Kephart D, Mann R, Storts D (2007) The versatility of the Maxwe $\|^{\circledR} 16$ system for genomic DNA extraction. Promega Notes 97:12-14. Available via http://www. promega.com/resources/articles/pubhub/promega-notes-2007/the-versatilityof-the-maxwell-16-system-for-genomic-dna-extraction document. Accessed 07 November 2012

Schloss PD (2008) Evaluating different approaches that test whether microbial communities have the same structure. ISME J 2(3):265-275

Schloss PD, Handelsman J (2008) A statistical toolbox for metagenomics: assessing functional diversity in microbial communities. BMC Bioinforma 9:34-48

Schloss PD, Westcott SL, Ryabin T, Hall JR, Hartmann M, Hollister EB, Lesniewski RA, Oakley BB, Parks DH, Robinson CJ, Sahl JW, Stres B, Thallinger GG, Van Horn DJ, Weber CF (2009) Introducing mothur: open-source, platformindependent, community-supported software for describing and comparing microbial communities. Appl Environ Microbiol 75(23):7537-7541

Schloss PD, Gevers D, Westcott SL (2011) Reducing the effects of PCR amplification and sequencing artifacts on 16S rRNA-based studies. PLoS One. doi:10.1371/journal.pone.0027310

Shipley MA, Koehler JW, Kulesh DA, Minogue TD (2012) Comparison of nucleic acid extraction platforms for detection of select biothreat agents for use in clinical resource limited settings. J Microbiol Methods J Microbiol Methods 91(1):179-183

Smith CJ, Osborn AM (2009) Advantages and limitations of quantitative PCR (QPCR)-based approaches in microbial ecology. FEMS Microbiol Ecol 67(1):6-20

Stach JE, Bathe S, Clapp JP, Burns RG (2001) PCR-SSCP comparison of 16S rDNA sequence diversity in soil DNA obtained using different isolation and purification methods. FEMS Microbiol Ecol 36:139-151

Stevenson BS, Drilling HS, Lawson PA, Duncan KE, Parisi VA, Suflita JM (2011) Microbial communities in bulk fluids and biofilms of an oil facility have similar composition but different structure. Environ Microbiol 13(4):10781090

Stults JR, Snoeyenbos-West O, Methe B, Lovley DR, Chandler DP (2001) Application of the 5 ' fluorogenic exonuclease assay (TaqMan) for quantitative ribosomal DNA and rRNA analysis in sediments. Appl Environ Microbiol 67 (6):2781-2789

van der Kraan GM, Bruining J, Lomans BP, van Loosdrecht MC, Muyzer G (2010) Microbial diversity of an oil-water processing site and its associated oil field: the possible role of microorganisms as information carriers from oilassociated environments. FEMS Microbiol Ecol 71(3):428-443

van der Kraan GM, de Ridder M, Lomans BP, Muyzer G (2011) Sampling and nucleic extraction procedures from oil reservoir samples. In: Whitby $C$ Skovhus TL (eds) Applied microbiology and molecular biology in oilfield systems. Springer Science and Business Media LLC, New York

Wang Q, Garrity GM, Tiedje JM, Cole JR (2007) Naive Bayesian classifier for rapid assignment of rRNA sequences into the new bacterial taxonomy. Appl Environ Microbiol 73(16):5261-5267

Wawrik B, Mendivelso M, Parisi VA, Suflita JM, Davidova IA, Marks CR, Van Nostrand JD, Liang Y, Zhou J, Huizinga BJ, Strąpoć D, Callaghan AV (2011) Field and laboratory studies on the bioconversion of coal to methane in the San Juan Basin. FEMS Microbiol Ecol 81(1):26-42

Wilson IG (1997) Inhibition and facilitation of nucleic acid amplification. Appl Environ Microbiol 63(10):3741-3751

Zhou J, Wu L, Deng Y, Zhi X, Jiang YH, Tu Q, Xie J, Van Nostrand JD, He Z, Yang Y (2011) Reproducibility and quantitation of amplicon sequencing-based detection. ISME J 5(8):1303-1313

\section{doi:10.1186/2191-0855-2-60}

Cite this article as: Oldham et al: Automated DNA extraction platforms offer solutions to challenges of assessing microbial biofouling in oil production facilities. AMB Express 2012 2:60. 